\title{
The effect of field size and luminance on spatial-frequency-dependent visible persistence and specific reading disability
}

\author{
W. L. SLAGHUIS \\ University of Tasmania, Hobart, Tasmania, Australia \\ and \\ W. S. LOVEGROVE \\ University of Wollongong, Wollongong, New South Wales, Australia
}

\begin{abstract}
The duration of visible persistence for sine-wave gratings was measured in 13-year-old normal and specific-reading-disabled children as a function of stimulus duration, field size, and luminance level. The results show that in specific-reading-disabled children, visible persistence is less sensitive to the effect of field size, suggesting that the two groups may differ in terms of spatialsummation processes.
\end{abstract}

A number of studies have shown that specific-readingdisabled (SRD) and normal readers exhibit a number of spatial-frequency-dependent differences in visual processing at threshold (Lovegrove, Bowling, Badcock, \& Blackwood, 1980; Lovegrove et al., 1982) and at suprathreshold levels (Badcock \& Lovegrove, 1981; Lovegrove, Heddle, \& Slaghuis, 1980; Slaghuis \& Lovegrove, 1985, 1986).

In threshold studies, it has been found that SRDs differ from normal readers on measures of temporal and pattern contrast sensitivity (Lovegrove et al., 1981; Lovegrove et al., 1982). The results of these studies have generally shown that SRDs are less sensitive than normal readers at low spatial frequencies- 1.0 to 4.0 cycles per degree (cpd)-and sometimes more sensitive at high spatial frequencies -12 to $16 \mathrm{cpd}$. It has also been shown that the nature of contrast sensitivity differences between SRDs and normal readers is influenced by stimulus luminance level but not by field size (Martin \& Lovegrove, 1984).

In a number of suprathreshold studies, it has been shown that SRDs differ from normal readers in spatialfrequency-dependent visible persistence durations (Badcock \& Lovegrove, 1981; Lovegrove et al., 1980; Slaghuis \& Lovegrove, 1985, 1986). In these studies, the term visible persistence refers to the continued visibility of a stimulus, after stimulus offset, that is phenomenally indistinguishable from that occurring during the actual presence of the stimulus. It has been shown that visible persistence is influenced by a number of stimulus vari-

W. L. Slaghuis's mailing address is: Department of Psychology, University of Tasmania, P.O. Box 252C, Hobart, Tasmania 7001, Australia. W. J. Lovegrove's address is: Department of Psychology, University of Wollongong, P.O. Box 1144, Wollongong, New South Wales 2500, Australia. ables, such as contrast (Bowling, Lovegrove, \& Mapperson, 1979), luminance (Bowen, Pola, \& Matin, 1984), stimulus duration (Bowling \& Lovegrove, 1980), and spatial frequency (Bowling \& Lovegrove, 1980; Meyer \& Maguire, 1977).

Lovegrove et al. (1980) found that for 8-year-old average readers the duration of visible persistence increased with spatial frequency (regression slope of 14.9), but that this function was significantly less in SRDs (a regression slope of 4.8). This slope difference indicates that the groups differ in their pattern of temporal processing across spatial frequency. Other studies have shown that spatialfrequency-dependent visible persistence durations in the SRD group are also differentially responsive to stimulus duration and contrast (Badcock \& Lovegrove, 1981; Slaghuis \& Lovegrove, 1985). At present, it is not known whether field size and stimulus luminance level have similar effects on visible persistence in SRDs and normal readers. It has previously been shown at threshold that the groups are similarly influenced by field size but not by luminance (Martin \& Lovegrove, 1984).

The present report, therefore, investigates the effect of field size and stimulus luminance on spatialfrequency-dependent visible persistence in SRDs and normal readers.

\section{METHOD}

\section{Subjects}

A SRD child is defined here as one of at least normal intelligence who has no known behavioral or organic disorder and who, despite normal schooling and average progress in other subjects, has a reading delay of at least 2.5 years. All control subjects were selected according to the same criteria except that their reading abilities were average or above average.

Each control subject was initially tested using the Junior Non-Verbal Test of intelligence (Australian Council for Educational Research, 1950), the Neale Analysis of Reading Ability (Neale, 1966), and the Landolt C 
acuity chart. In addition to these tests, the SRD group was also assessed using the Wechsler Intelligence Scale for Children-Revised (WISC-R; Wechsler, 1974). A total of 12 male control and 12 male SRD subjects were included. The control and SRD groups had mean ages of 12 years, 4 months and 12 years, 5 months and mean reading ages of 12 years, 1 month and 8 years, 8 months, respectively. The SRD group had a mean reading delay of 3 years, 9 months, which was found to be significantly different from that of the control group $[t(24)=14.7$, $p<.01]$. The mean Junior Non-Verbal IQs for the SRD and control groups were 109.5 and 99.9 , respectively. These were significantly different $[t(24)=2.93, p<.05]$. The mean WISC-R subscale IQ scores for the SRDs were 97.4 for the verbal IQ, 104 for the performance IQ, and $\mathbf{1 0 0 . 2}$ for the full-scale IQ.

\section{Stimuli and Apparatus}

Stimuli were photographic prints of vertical sinusoidal gratings presented by means of a Scientific Prototype (Model GB) three-channel tachistoscope in a darkened room with an average luminance of $2.93 \mathrm{~cd} / \mathrm{m}^{2}$. They had a contrast of 0.3 . The space-average luminance of the gratings and of the blank field with which they were alternated was kept constant at each of two luminance levels, $34.2 \mathrm{~cd} / \mathrm{m}^{2}$ (high) and $5.8 \mathrm{~cd} / \mathrm{m}^{2}$ (low), measured using a Tektronix J6523 $1^{\circ}$ narrow-angle luminance probe. The size of the circular viewing field was varied and subtended a visual angle of $1.4^{\circ}$ (small) and $4.0^{\circ}$ (large).

\section{Procedure}

The data were analyzed using a five-factor analysis of variance with reading ability being a between-groups factor. Subjects received all combinations of levels of the other factors (spatial frequency, duration, luminance, and field size).

Subjects were familiarized with the equipment and procedure and were given a 20-min practice session. The procedure was identical to that described in Slaghuis and Lovegrove (1985).

Each subject performed a total of 16 blocks of trials; each block represented one stimulus condition. Each stimulus condition consisted of one of two spatial frequencies ( 2 or $12 \mathrm{cpd}$ ), at one of two durations $(80$ and $300 \mathrm{msec})$, at one of two luminance levels $\left(34.2\right.$ and $\left.5.8 \mathrm{~cd} / \mathrm{m}^{2}\right)$, and at one of two field sizes $\left(1.4^{\circ}\right.$ and $\left.4.0^{\circ}\right)$. The order of presentation of stimulus conditions was randomized. All stimuli were presented binocularly.

\section{RESULTS AND DISCUSSION}

The log transformed means for each group at each duration, field size, luminance, and spatial frequency are shown in Figure 1.

A five-way analysis of variance resulted in a marginally significant groups difference $[F(1,22)=3.71, p=.08]$, indicating a trend for longer durations of visible persistence in the SRD group.

In line with previous research, several main effects were found to be significant. A significant spatial frequency main effect was found $[F(1,22)=710, p \leq .01]$ and was due to visible persistence increasing with increasing spatial frequency. A significant duration main effect was also found $[F(1,22)=307.8, p<.01]$ and resulted from decreased durations of visible persistence with increasing stimulus duration. The luminance main effect was also significant $[F(1,22)=11.9, p<.01]$, indicating that visible persistence decreased with increasing luminance level. The field size main effect was significant $[F(1,22)=14.96, p<.001]$ and was due to visible persistence decreasing with increasing field size. It should be noted that this experiment does not differentiate be-

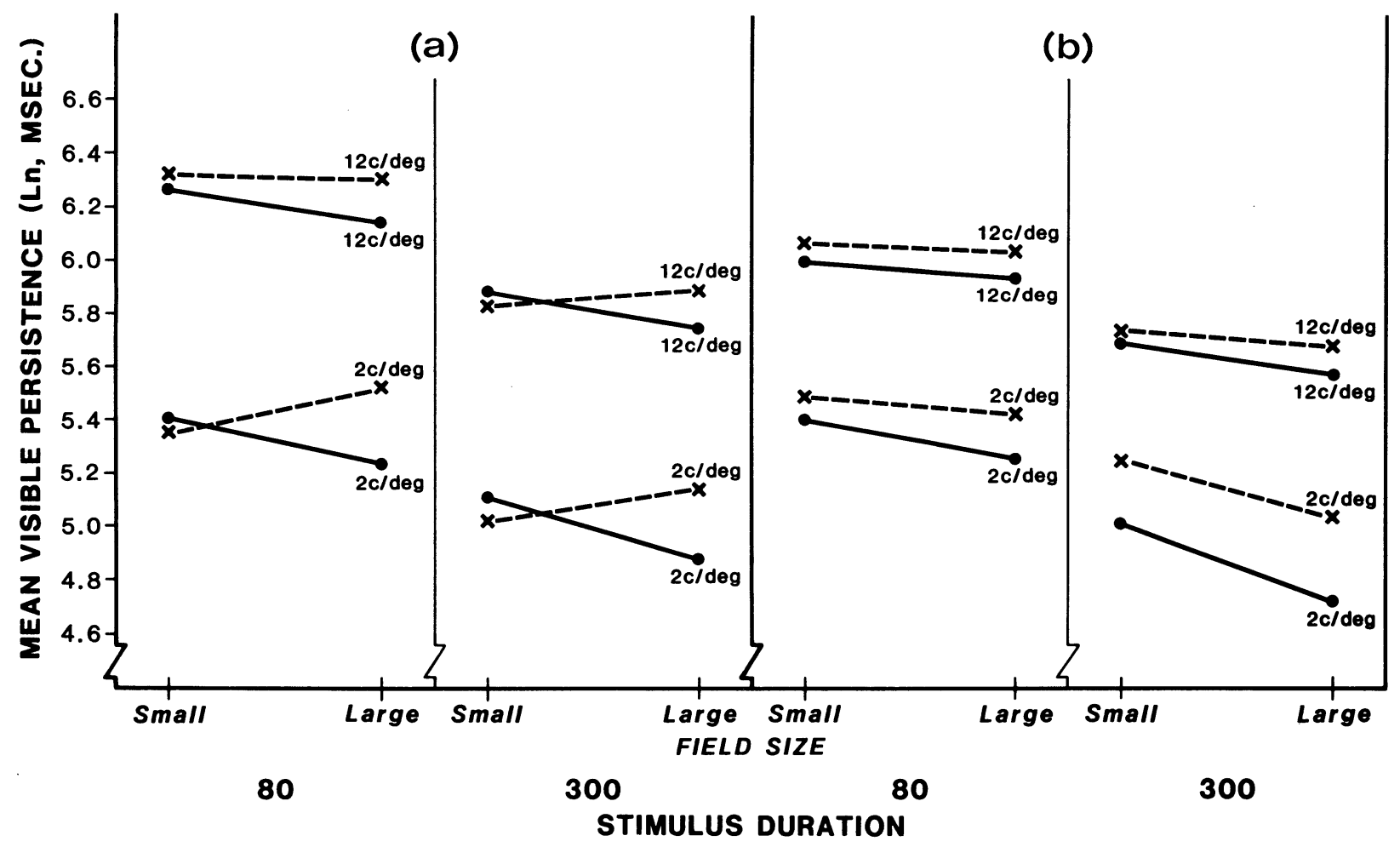

Figure 1. Ln duration visible persistence of each reading ability group (dashed line represents SRDs, solid line represents controls) as a function of spatial frequency, stimulus duration, luminance, and field size. Panel a shows the low-luminance and Panel b shows the high-luminance data. 
tween the effects of field size per se and the increase in number of cycles that results from the increasing field size. This issue is not directly relevant here (for a discussion of this issue, see Lovegrove \& Meyer, 1984).

The groups $\times$ spatial frequency interaction was found to be marginally significant $[F(1,22)=3.43, p=.07]$. This showed that there was a trend for visible persistence to increase with increasing spatial frequency at a faster rate in the control group than in the SRD group, in line with previous results (Badcock \& Lovegrove, 1981; Slaghuis $\&$ Lovegrove, 1985, 1986). The groups $\times$ duration $\times$ spatial frequency interaction was significant $[F(1,22)=4.79, p<.05]$. This resulted from the fact that differences in slope between the two groups were greater with a $300-\mathrm{msec}$ than with an $80-\mathrm{msec}$ stimulus duration. These results are consistent with previous investigations of these effects.

The groups $\times$ field size interaction was found to be significant $[F(1,22)=10.45, p<.01]$. From Figure 1, it can be seen that in normal readers, averaged across all conditions, visible persistence decreased with increasing field size. However, in the SRD group there was a slight trend for persistence duration to increase with increasing field size. The groups $\times$ field size $\times$ spatial frequency interaction was also found to be marginally significant $[F(1,22)=3.83, p=.062]$. As this effect is only marginally significant and results from a number of small and inconsistent effects, it is hard to interpret.

The groups $\times$ luminance $[F(1,22)=0.14, p>.05]$ and the groups $\times$ duration $[F(1,22)=.02, p>.05]$ interactions were both nonsignificant. However, the groups $\times$ luminance $\times$ duration interaction was marginally significant $[F(1,22)=3.6, p=.07]$. Again, as this effect is only marginal and not related to any clear and consistent trends, it may not be important. The remaining higher order interactions were all nonsignificant.

The results of this experiment show that visible persistence in SRDs is less sensitive to the effects of increasing field size, which may indicate a problem with spatialsummation processes. The fact that visible persistence in SRDs is less sensitive to the effect of field size is in line with previous research showing that SRDs are also less sensitive to the effects of contrast, spatial frequency, and stimulus duration (Badcock \& Lovegrove, 1981; Slaghuis \& Lovegrove, 1985). In sum, the results of this experi- ment confirm the results of previous studies and broaden their generality.

\section{REFERENCES}

Australian Council for Educational Research. (1950). Junior Non-Verbal Test. Hawthorne, Victoria, Australia: Author.

BADCOCK, D., Lovegrove, W. J. (1981). The effect of contrast, stimulus duration and spatial frequency on visible persistence in normal and specifically disabled readers. Journal of Experimental Psychology: Human Perception \& Performance, 7, 495-505.

Bowen, R. W., Pola, J., \& Matin, L. (1974). Visual persistence: Effects of flash luminance, duration and energy. Vision Research, 14, 295-303.

Bowling, A., \& Lovegrove, W. J. (1980). The effects of stimulus duration on the persistence of gratings. Perception \& Psychophysics, 27, 574-578.

Bowling, A., Lovegrove, W., \& Mapperson, B. (1979). The effect of spatial frequency and contrast on visible persistence. Perception, 8, 529-539.

Haber, R. N., \& Standing, L. (1970). Direct measures of the apparent duration of a flash. Canadian Journal of Psychology, 24, 216-229.

Lovegrove, W. J., Bowling, A., BADCoCK, D., \& Blackwood, M. (1980). Specific reading disability: Differences in contrast sensitivity as a function of spatial frequency. Science (Washington), 210, 439-440.

Lovegrove, W. J., Heddle, M., \& Slaghuis, W. L. (1980). Reading disability: Spatial frequency and specific deficits in visual information store. Neuropsychologia, 18, 111-115.

Lovegrove, W. J., Martin, F., Bowling, A., Blackwood, M., BaDCOCK, D., \& PAXTON, S. (1982). Contrast sensitivity functions and specific reading disability. Neuropsychologia, 20, 309-315.

Lovegrove, W. J., \& MeYer, G. E. (1984). Visible persistence as a function of spatial frequency, number of cycles and retinal area. Vision Research, 24, 255-259.

Martin, F., \& Lovegrove, W. J. (1984). The effects of field size and luminance on contrast sensitivity differences between specifically reading disabled and normal children. Neuropsychologia, 22, 73-77.

MeYER, G., \& MAGuire, W. M. (1977). Spatial frequency and the mediation of short term visual storage. Science (Washington), 198, 524-525.

Neale, M. D. (1966). The Neale Analysis of Reading Ability. London: Macmillan.

Slaghuis, W. L., \& Lovegrove, W. J. (1985). Spatialfrequency-dependent visible persistence and specific reading disability. Brain \& Cognition, 4, 219-240.

Slaghuis, W. L., \& Lovegrove, W. J. (1986). The effect of physical flicker on visible persistence in normal and specifically disabled readers. Australian Journal of Psychology, 38, 1-11.

WeChSLER, D. (1974). Wechsler Intelligence Scale for ChildrenRevised. New York: The Psychological Corporation.

(Manuscript received for publication August 2, 1986.) 